\title{
Using Nano Zero-Valent Iron Supported on Diatomite to Remove Acid Blue Dye: Synthesis, Characterization, and Toxicology Test
}

\author{
Ernesto Flores-Rojas ${ }^{1}$, Denhi Schnabel ${ }^{2}$, Erick Justo-Cabrera ${ }^{2}$, Omar Solorza-Feria ${ }^{3} \mathbb{C}$, Héctor M. Poggi-Varaldo ${ }^{4}$ \\ and Luz Breton-Deval ${ }^{2,5, *}$ \\ 1 Campus San Rafael, Universidad del Valle de México, Mexico City 06740, Mexico; erefrojas@gmail.com \\ 2 Instituto de Biotecnología, Universidad Nacional Autónoma de México, Cuernavaca 62210, Mexico; \\ denhi.schnabel@ibt.unam.mx (D.S.); erickjustoc@gmail.com (E.J.-C.) \\ 3 Programa de Nanociencias y Nanotecnología, Centro de Investigación y de Estudios Avanzados del Instituto \\ Politécnico Nacional, Mexico City 07360, Mexico; osolorza@cinvestav.mx \\ 4 Environmental Biotechnology and Renewable Energies Group, Department of Biotechnology and \\ Bioengineering, CINVESTAV-IPN, Mexico City 07360, Mexico; lazarillodetormes1001@gmail.com \\ 5 Consejo Nacional de Ciencia y Tecnología, Mexico City 03940, Mexico \\ * Correspondence: luz.breton@ibt.unam.mx
}

check for updates

Citation: Flores-Rojas, E.; Schnabel, D.; Justo-Cabrera, E.; Solorza-Feria,

O.; Poggi-Varaldo, H.M.;

Breton-Deval, L. Using Nano

Zero-Valent Iron Supported on

Diatomite to Remove Acid Blue Dye: Synthesis, Characterization, and Toxicology Test. Sustainability 2021, 13, 13899. https://doi.org/10.3390/ su132413899

Academic Editor: Petros Kokkinos

Received: 1 September 2021

Accepted: 4 December 2021

Published: 16 December 2021

Publisher's Note: MDPI stays neutral with regard to jurisdictional claims in published maps and institutional affiliations.

Copyright: (c) 2021 by the authors. Licensee MDPI, Basel, Switzerland. This article is an open access article distributed under the terms and conditions of the Creative Commons Attribution (CC BY) license (https:/ / creativecommons.org/licenses/by/ $4.0 /)$.

\begin{abstract}
This work aimed to synthesize and characterize nanoscale zero-valent iron (nZVI), supported on diatomaceous earth (DE) at two different molar concentrations, 3 and 4 M (nZVI-DE-1 nZVI-DE-2), to test the decolorization treatment of acid blue dye (AB) and perform a toxicological test using zebrafish. The synthesis of the nanoparticles was obtained using the chemical reduction method. The material was fully characterized by X-ray diffraction, scanning electron microscopy (SEM), energy-dispersive X-ray (EDX), and transmission electron microscopy and specific surface area (BET). The results showed spherical forms in clusters between 20 and $40 \mathrm{~nm}$ of zero-valent iron supported on diatomaceous earth. The removal of $1 \mathrm{~g} / \mathrm{L}$ of AB from water treated with nZVI-DE-1 and nZVI-DE-2 reached the decolorization of $90 \%$ and $98 \%$ of all dye. By contrast, controls such as nZVI and DE-1 and DE-2 removed $40 \%, 37 \%$, and $24 \%$ of the dye. Toxicological analysis using zebrafish showed that $\mathrm{AB}$ causes a severe defect in development, and embryos die after exposure. However, the water samples treated with nZVI-DE-1 and nZVI-DE-2 are not harmful to the zebrafish embryos during the first $24 \mathrm{~h}$. However, all embryos exposed to the new material for more than $48 \mathrm{hpf}$ had cardiac edema, smaller eyes, and curved and smaller bodies with less pigmentation.
\end{abstract}

Keywords: nanoparticles; water treatment; dyes; zero-valent iron; acid blue

\section{Introduction}

Textile industries discharge into wastewater without any treatment around 100 tons of dyes worldwide [1]. The concentration of dyes in industrial effluents can reach $500 \mathrm{mg} / \mathrm{L}$ and pollute local freshwater, reducing the efficiency of sunlight and thereby impeding photosynthesis. [2]. As a result, the stream's water temperature decreases, and photoautotrophic organisms such as algae, euglena, and cyanobacteria can no longer survive [3]. The death of these organisms is an ecological loss because they play an essential role in the cycle of nutrients and can absorb organic matter present in the stream. They can also remove carbon dioxide from the atmosphere and are the base of the entire upper food chain [4]. Other parameter levels affected by the dye pollution are the biochemical oxygen demand (DBO), chemical oxygen demand (COD), and total suspended solids (TSS). These changes in the water quality composition could promote the death of fish and amphibians and change the microbial community [5]. Furthermore, the local population lost a valuable freshwater resource. 
Acid blue $(\mathrm{AB})$ is an anthraquinone dye, one of the most widely used colorants in the industrial sector, including cosmetics, food coloring, or dyeing different fibers. It is commonly mixed with sulfuric acid to make it more soluble before any industrial application, increasing toxicity [6]. AB is not only toxic for aquatic life but can also cause skin irritation, cornea damage, and promote the development of tumors and cancer [7]. Several kinds of research have been carried out with the aim of removing dyes from water using aerobic or anaerobic degradation, filtration, adsorption, membrane filtration, and other methods [8-10]. However, these processes have disadvantages, such as the extended time required for the treatment, high operational costs, and efficiency [11]. Dye pollution is not a novel problem; in fact, it is a persistent problem without a solution. The best solution made by some countries is to move their industries to poor lands lacking rules.

Recently, nanomaterials have been used to remove several pollutants, including dyes such as crystal violet [12], methyl orange [13], acid red 88, and Black 5 [14]. Nanoparticles have a relatively high surface-area-to-mass ratio, rendering them more reactive than conventional materials used for water treatment [15]. Iron is the material most used in several remediation treatments due to its low cost, abundance, ease, and reactivity. These materials remove dyes through an adsorption and reduction process [16]. However, this technology has to overcome some challenges to be applied successfully; during synthesis, the nanoparticles aggregate easily, thereby losing surface area $[17,18]$ and becoming toxic for aquatic life [19]. To avoid these problems, some researchers added surfactants to nanoparticles or supported them [20]. The material used to support nanoparticles needs to be affordable, accessible, and compatible with the nanoparticles [21]. The diatomite earth is an affordable and well-known filter material in the industry, used to remove ammonium ions [22], heavy metals [23], and even some dyes such as Red 3BS and Yellow 5GF [24] using their absorption capacity. This material could be an exciting material to support the zero-valent iron nanoparticles and make an efficient filter scalable to an industrial application.

An optimal filter is affordable, removes high levels of the pollutant, and is safe to the user. Zebrafish (Danio rerio) has been established as an ideal model for toxicological studies to test the effects of contaminants such as alkaloids, glycosides, metals, alcohols, and carboxylic acids, among others [25-27]. Zebrafish have many characteristics that make them a good model for testing toxicity. Firstly, female zebrafish are able to produce hundreds of eggs, and embryos are transparent, which allows for a close observation of their development under a microscope. Secondly, the rapid growth of zebrafish compared to other vertebrates makes it an ideal model for high-throughput analysis [28].

Therefore, the objective of this research was to characterize and synthesize nanoscale zero-valent iron supported on diatomaceous earth and test if treated water had a negative effect on the viability of zebrafish embryos.

\section{Materials and Methods}

\subsection{Preparation of Diatomite Earth and Synthesis of Nanomaterial}

The diatomite earth (DE) was washed with $1 \mathrm{M} \mathrm{HCl}$ for $8 \mathrm{~h}$ under agitation (150 rpm). After the acid-washed, the DE was rinsed with water before using it as nZVI support. Two types of nZVI-DE were synthesized. The first identified as nZVI-DE-1 was prepared from $0.3 \mathrm{M} \mathrm{FeCl}_{2} \cdot 4 \mathrm{H}_{2} \mathrm{O}$ at a $40 / 60$ proportion of $\mathrm{FeCl}_{2} \cdot 4 \mathrm{H}_{2} \mathrm{O} / \mathrm{DE}$, while the second type identified as nZVI-DE-2 was made at a 50/50 ratio of $\mathrm{FeCl}_{2} \cdot 4 \mathrm{H}_{2} \mathrm{O} / \mathrm{DE}$. nZVI and nZVI-DE-1 and -2 were obtained using the chemical reduction method of $\mathrm{FeCl}_{2} \cdot 4 \mathrm{H}_{2} \mathrm{O}$ in an aqueous solution using $\mathrm{NaBH}_{4}$ as a reducing agent, due to its simplicity and efficiency in securing nZVI [29]. The $\mathrm{FeCl}_{2} \cdot 4 \mathrm{H}_{2} \mathrm{O}$ and $\mathrm{DE}$ were added to a previously ethanol deoxygenated by bubbling it with $\mathrm{N}_{2}$ gas for $30 \mathrm{~min}$. The iron salt was dissolved in $50 \mathrm{~mL}$ ethanol, and the solution was kept under $\mathrm{N}_{2}$ bubbling and stirring for $30 \mathrm{~min}$ at $400 \mathrm{rpm}$ at $25^{\circ} \mathrm{C}$. Later, $1.5 \mathrm{M} \mathrm{NaBH}_{4}$ solution was slowly added into the $\mathrm{FeCl}_{2} / \mathrm{DE}$ solution. After the reaction, the solution was kept stirring at $700 \mathrm{rpm}$ for $60 \mathrm{~min}$. In the end, both types of nZVI-DE were washed 10 times with ethanol and dried in an oven, bubbling with argon at $50{ }^{\circ} \mathrm{C}$. The synthesis of the nZVI without DE support followed the same technique. 


\subsection{Characterization of Iron Nanoparticles Supported DE}

The XRD analysis was carried out using a Bruker D8 Advance Eco diffractometer coupled with a copper source without a monochromator; the samples were placed in a sample holder with a $2 \theta$ range of $5-130^{\circ}$ at a size and time of $0.02^{\circ}$ and $0.2 \mathrm{~s}$. The analysis of the crystalline phases was carried out using Match software.

A scanning electron microscope (SEM) HRSEM-AURIGA Zeiss integrated with an $X$-ray scattered energy (EDX) analyzer at a voltage of $1-10 \mathrm{keV}$ at a high vacuum was used. Both the mapping and the elemental compositional analysis were carried out by selecting random areas using the EDX analyzer three times per sample. The samples were placed on graphite tape supported on metal discs.

A transmission electron microscope (TEM) JEM-ARM200F operated at a high vacuum was used to describe the morphology, size, and distribution of the particles. The samples were prepared by dispersing a small amount of powder in absolute ethanol with the aid of an ultrasonic bath. The dispersion $(10 \mu \mathrm{L})$ was applied on a copper mesh for TEM of 300 mesh with Lacey/Carbon film and allowed to evaporate in a desiccator. We used Digital Micrograph to calculate the particle size.

The specific surface area was measured using the Brunauer-Emmett-Teller (BET) method of $\mathrm{N}_{2}$ adsorption, using a Micromeritics Gemini 2360 surface area analyzer. Before analysis, the samples were degassed under vacuum at $70{ }^{\circ} \mathrm{C}$ for three hours.

\subsection{Batch Degradation Experiments}

The acid blue 52 is an anthraquinone dye with the following molecular formula $\mathrm{C}_{22} \mathrm{H}_{15} \mathrm{~N}_{3} \mathrm{NA}_{2} \mathrm{O}_{9} \mathrm{~S}_{2}$, a molecular weight of 575.48 , and a CAS registry number of 61752-67-8. The experiment consisted of comparing two different relationships between the quantity of nZVI and DE (nZVI-DE-1 = 40/60, and nZVI-DE-2 $=50 / 50$ ) but held the same amount of iron $(62 \mathrm{mg})$ in every treatment.

The experiment was carried out using serum bottles with $50 \mathrm{~mL}$ of water contaminated with dye (1000 mg/L) loaded with $658 \mathrm{mg}$ of Nano nZVI-DE. The controls were (i) DE-1 and DE-2 to evaluate dye degradation to adsorption process, (ii) nZVI to assess the effect of free nanoparticles without the support, and (iii) AD to calculate the abiotic degradation. The experiments were carried out at $25^{\circ} \mathrm{C}$ with a mix of $150 \mathrm{rpm}$ and $\mathrm{pH}$ 7.4. All experiments were performed in triplicate. The removal of $\mathrm{AB}$ was measured with the UV spectra (BioSpectrometer, Eppendorf) at $526 \lambda \mathrm{nm}$.

\subsection{Fish Maintenance and Strains}

$\mathrm{AB}$ line and wild-type zebrafish (Danio rerio) embryos were obtained from natural crosses and raised at $28{ }^{\circ} \mathrm{C}$ based on standard procedures [30]. Eggs were obtained by random pairwise mating of zebrafish. The following morning, the eggs were harvested and transferred into plastic Petri dishes (60 eggs per dish) containing $10 \mathrm{~mL}$ fresh embryo water. Further, unfertilized, unhealthy, and dead embryos were identified under a dissecting microscope and removed. Morphological criteria determined embryonic stages, according to Kimmel and collaborators [31]. Zebrafish were handled in compliance with local animal welfare regulations, and all protocols were approved by the ethics committee (Instituto de Biotecnología, UNAM, Mexico City, México).

\subsection{Toxicological Studies}

At $3.5 \mathrm{~h}$ postfertilization (hpf), embryos were again screened, and any additional dead and unhealthy embryos were removed. Embryos at the sphere stage were selected and transferred into a 48-well plate, with 10 in each well. Later, the embryo water was absorbed, and $300 \mu \mathrm{L}$ of the treated water samples (AB dye, nZVI-DE-1, nZVI-DE-2, DE-1, DE-2) was loaded into each well; experiments were performed in triplicate. The control was a set of embryos grown with embryonic water in the same plate as well as in a petri dish independently. The embryonic plates were cultivated in a moist chamber at $28^{\circ} \mathrm{C}$ from 6 to $24 \mathrm{hpf}$, and the viability of the embryos was observed under a dissecting microscope. 
Embryos at $24 \mathrm{hpf}$ were anesthetized with tricaine, immobilized with methylcellulose on agar plates and visualized with a stereomicroscope (Leica MZ 12.5), and photographed using a CCD camera (AxioCam MRc 5, Zeiss) and AxioVision Rel. 48 software. Statistical analysis was performed with three independent experimental replicates. The exact number of biological replicates is indicated in the figure legends. Statistical analysis was performed with Prism (GraphPad) Student's t-test. Error bars in column graphs represent the standard deviation of the mean (s.d.).

\section{Results}

\subsection{Characterization of DE and Iron Nanoparticles}

According to the results, DE presents a Brunauer-Emmett-Teller (BET) specific surface area of $23 \mathrm{~m}^{2} / \mathrm{g}$ with a pore volume of $0.56 \mathrm{~cm}^{3} / \mathrm{g}$. This result is in accordance with another research published previously (Crane and Sapsford, 2018). The homogenous pore volume allows the molding of narrow-sized particles dispersed homogeneously on their internal surfaces [32]. Regarding the composition, the SEM/EDX analysis of DE showed high levels of oxygen at around 52\%, given that most of the materials that form DE are oxides, such as silicon oxide or aluminum oxide (Table 1 ).

Table 1. Element composition of the materials.

\begin{tabular}{ccccc}
\hline Element & DE & nZVI & nZVI-DE-1 & nZVI-DE-2 \\
\hline Si & $36.7 \pm 1.1$ & ND & $23.9 \pm 2.9$ & $23.3 \pm 0.6$ \\
$\mathrm{Al}$ & $8.6 \pm 1.5$ & ND & $8.4 \pm 0.2$ & $7.0 \pm 0.3$ \\
$\mathrm{O}$ & $52.1 \pm 0.1$ & 19.27 & $43.2 \pm 2.2$ & $42.1 \pm 0.3$ \\
$\mathrm{~S}$ & $0.9 \pm 0.1$ & $\mathrm{ND}$ & $1.3 \pm 0.5$ & $1.2 \pm 0.3$ \\
$\mathrm{~K}$ & $0.5 \pm 0.1$ & $\mathrm{ND}$ & $0.7 \pm 0.3$ & $0.7 \pm 0.2$ \\
$\mathrm{Fe}$ & $\mathrm{ND}$ & 80.73 & $21.9 \pm 2.3$ & $24.9 \pm 0.5$ \\
\hline
\end{tabular}

The second most abundant element in DE is $\mathrm{Si}(37 \%)$, as was expected and elsewhere reported [33]. The Si content varies depending on the physicochemical conditions present during the formation of the DE bank [34]. These minor variations could affect the material's performance. The higher the content of $\mathrm{Si}$, the more silanol groups available to react with polar organic compounds, increasing the number of compounds adsorbed by DE [35]. Carbonate minerals can also affect the number of compounds that DE can be absorbed, because the deposit of this material along the diatomite structure reduces its porosity [34].

The XRD analysis showed several crystal structures formed in the DE with the abundance of cristobalite, berlinite, calcite, Kaolinite, feldspar, and quartz (Figure 1a). Regarding nZVI-DE-1 and nZVI-DE-2, TEM images showed spherical forms in clusters between 20 and $40 \mathrm{~nm}$, with an average size of $35 \pm 8 \mathrm{~nm}$ (Figure 2a,b). The SEM/EDX analysis showed a decrease in the levels of $\mathrm{Si}$ and $\mathrm{O}$ compared with the DE analysis given that space is occupied by iron $22 \%$ and $25 \%$ for nZVI-DE-1 and nZVI-DE-2, respectively (Table 1). The XRD pattern of nZVI-DE showed diffraction peaks at the $2 \theta$ of $44.90^{\circ}$, confirming the presence of zerovalent iron in both treatments of nZVI-DE and on nZVI treatment (Figure 1b). Crane and Sapsford et al. [36] have reported similar XRD patterns of iron and DE. However, they indicate the presence of other metals such as Al, suggesting that perhaps the duration of the acid wash $\sim 2 \mathrm{~h}$ was not enough. 

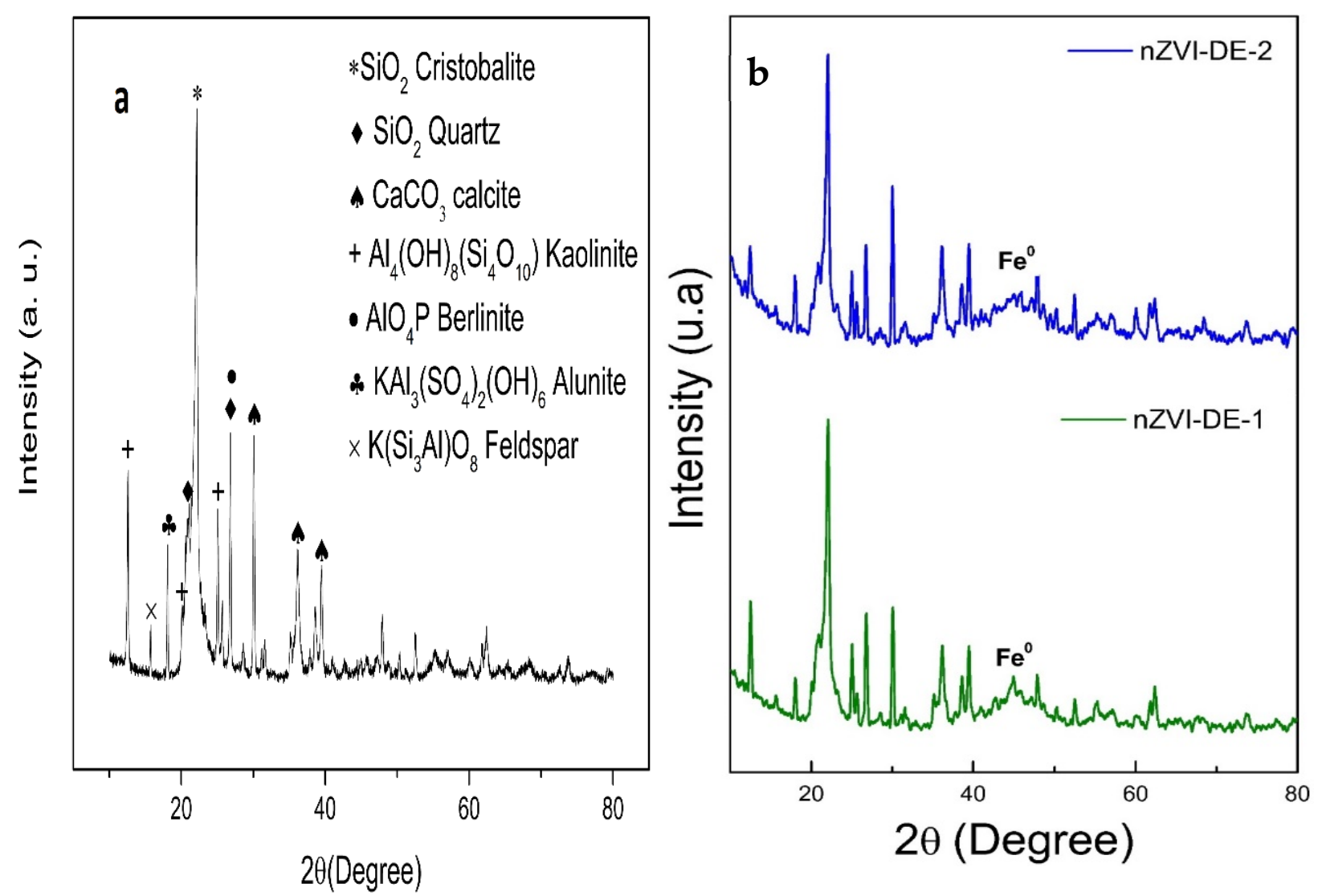

Figure 1. (a) XRD pattern of diatomaceous earth. (b) XRD pattern of nZVI-DE-1 and nZVI-DE-2 treatments.
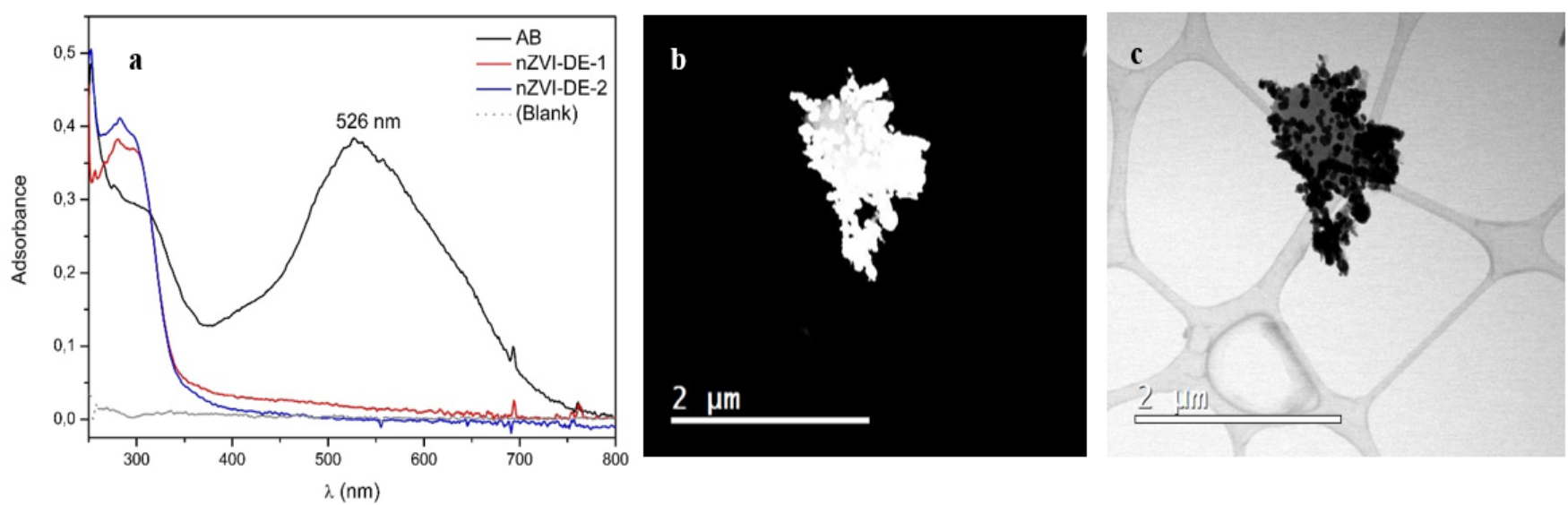

Figure 2. (a) Absorbance signal of the dye and the dye removed by the nZVI-DE-1 and -2, while dark field (b) and bright field (c) micrographs of the Fe nanoparticles decorating DE particles. Fe nanoparticles brighter on dark field contrast with those of the bright field.

\subsection{Batch Degradation Experiments}

The reaction proceeded in the first $5 \mathrm{~min}$ with a drastic change of color, and later, the difference decelerated and stopped 7 min later. Figure 2a shows the UV-vis spectra taken $10 \mathrm{~min}$ after, when the reaction was stable. The black line shows the spectra of the water with $1 \mathrm{~g} / \mathrm{L}$ of $\mathrm{AB}$, the red line indicates the nZVI-DE-1 treatment, which removed $90 \%$ of the pigment, and the blue line shows that the nZVI-DE-2 treatment achieved $98 \%$ removal of AB. The nZVI control removed just $40 \%$ of AB, and DE- 1 and DE- 2 controls removed $37 \%$ and $24 \%$, respectively.

The contrast between the catalytic power of supported and unsupported nanomaterials is significant: nZVI-DE-1 and nZVI-DE-2 removed 50 and 58\% more dye than 
unsupported nanoparticles. In nZVI-DE-1 and nZVI-DE-2, the nZVI particles removed the dye through reduction and adsorption processes [13,37]. At the same time, the DE played a protective role for the nZVI catalyst (reducing agglomeration) and contributed to the adsorption of $\mathrm{AB}$. The amount of $\mathrm{AB}$ removed and adsorbed could be calculated based on removal results of nZVI and DE controls, and evidently, around 40-50\% of the removal was adsorbed by the DE, and the rest was the reduction performed by the nanoparticles. Another factor that could contrast the removal of both treatments could be the amount of DE. nZVI-DE-1 had less DE where nanoparticles were supported, and this treatment also had less iron than nZVI-DE-2.

The removal performed by the nanoparticles in contact with the contaminant occurs because the nanoparticles play a role as electron mediators; moreover, $\mathrm{H}$ atoms are generated, which causes the break of the double bond $(-\mathrm{C}=\mathrm{C}-)$, eliminating the chromophore group of the dye [38]. By destroying one of the critical components of the dye, the absorption peak at a wavelength of $526 \mathrm{~nm}$ was reduced as a result. At the same time, $\mathrm{Fe}^{\circ}$ reacted and formed oxides such as $\mathrm{FeO}_{2}, \mathrm{FeO}_{3}$, and $\mathrm{FeOH}$, which have a high capacity to absorb some molecules of the pollutant [39]. However, this capacity to absorb could be affected by internal changes in $\mathrm{pH}$ [40]. The $\mathrm{pH}$ of the dye solution plays an essential role in the entire adsorption process and the adsorption capacity, influencing loads of the nZVI-DE and DE. This changes the degree of ionization and dissociation of the functional groups in the active sites of the adsorbent materials [41]. In the beginning, the $\mathrm{pH}$ of the treatments was 7.4. However, at the end of the removal experiments, nZVI-DE-1 had 8.9, and nZVI-DE-2 had 8.7, while nZVI had a more neutral pH of 7.7 and DE- 1 and -2 had an acid pH of 4 and 4.6, respectively. The treatment with nanoparticles showed $\mathrm{pH}$ values around 8 because the dye removal is a dynamic process where $\mathrm{Fe}^{\circ}$ nanoparticles begin to be transformed into oxides as $\mathrm{Fe}^{2+}, \mathrm{Fe}^{3+}, \mathrm{Fe}(\mathrm{OH})_{3}$, and $\mathrm{Fe}(\mathrm{OH})_{2}$, which reduces the quantity of $\mathrm{H}^{+}$and raises the $\mathrm{pH}$ of the liquid [42], whereas in the treatment with only DE, the $\mathrm{pH}$ of the solutions finishes acidic due to the protonation of surface silanol groups where protons are forming conjugate acids that lower the $\mathrm{pH}[43,44]$.

\subsection{Toxicological Analysis of Treated Water on Zebrafish Embryos}

Embryos were treated with $\mathrm{AB}$, and the water was treated with nZVI-DE-1, nZVI-DE-2, DE-1, and DE-2 during 24, 48, 72, and 96 h postfertilization (hpf). Embryos exposed only to $\mathrm{AB}$ died after treatment; meanwhile, embryos treated with nZVI-DE-1 and nVZI-DE-2 developed alongside the embryos in control water (Figure 3A-C,G). Embryos grown in the presence of DE developed regularly (data not shown). The embryos treated with nZVIDE-1 and nZVI-DE-2 were allowed to develop until $24 \mathrm{hpf}$; embryos developed normally, but a slight developmental delay was observed compared to the control (Figure 3D-F). However, after $24 \mathrm{~h}$ of culture, particles associated with the chorion were visible in nZVI-DE-1 and nZVI-DE-2 samples, possibly due to an agglomeration of nanoparticles (Figure 3B,C asterisk), and perhaps, this caused the developmental delay observed in these samples. At 48 and $72 \mathrm{hpf}$ (data not shown), there was no difference in the viability of the embryos when compared to the control (Figure 3N). Still, an unambiguous effect in the morphology of the embryos was observed as all of the embryos had cardiac edema, smaller eyes, and curved and smaller bodies with less pigmentation (Figure 3H-O). We also observed particles attached to the chorion (Figure $3 \mathrm{~A}-\mathrm{C}, \mathrm{J}$ ); these could be the nanoparticles since we did not observe these aggregates in the control embryos. At $96 \mathrm{hpf}$, the embryos treated with the water from nZVI-DE-1 and nZVI-DE-2 died; meanwhile, control embryos developed normally. The delay in development at $24 \mathrm{hpf}$; the morphological effect at 48 and $72 \mathrm{hpf}$ and the comprised viability of embryos at $96 \mathrm{hpf}$ could be due to the presence of the nanoparticles. Previous work conducted by Almeida et al. [45] showed that embryos exposed to iron micro- and nano-particles had effects. 
Control
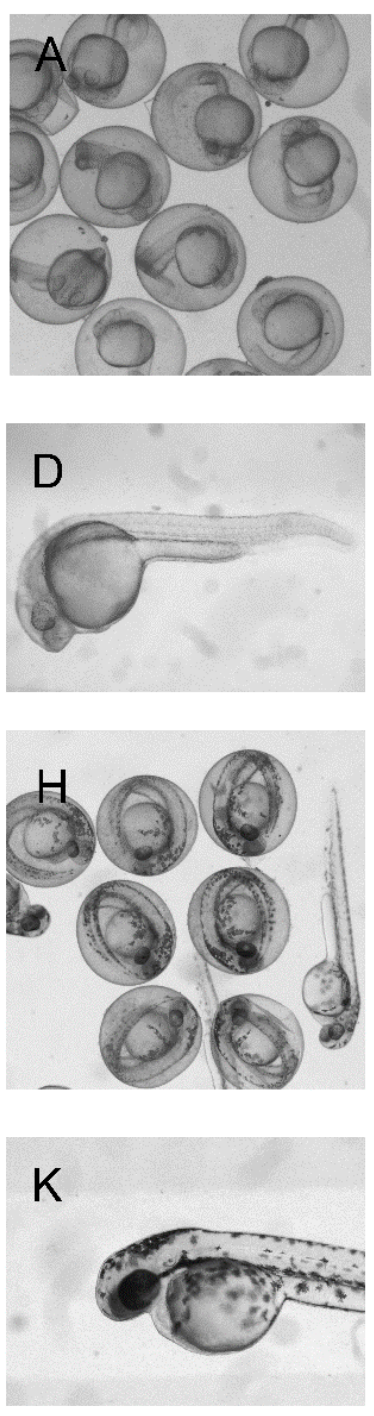

nZV-DE-1
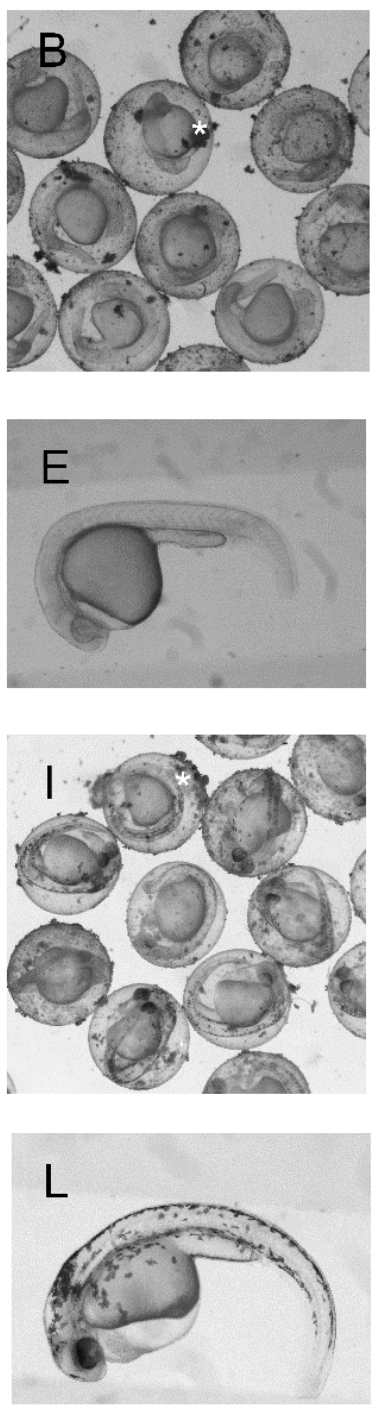

nZV-DE-2
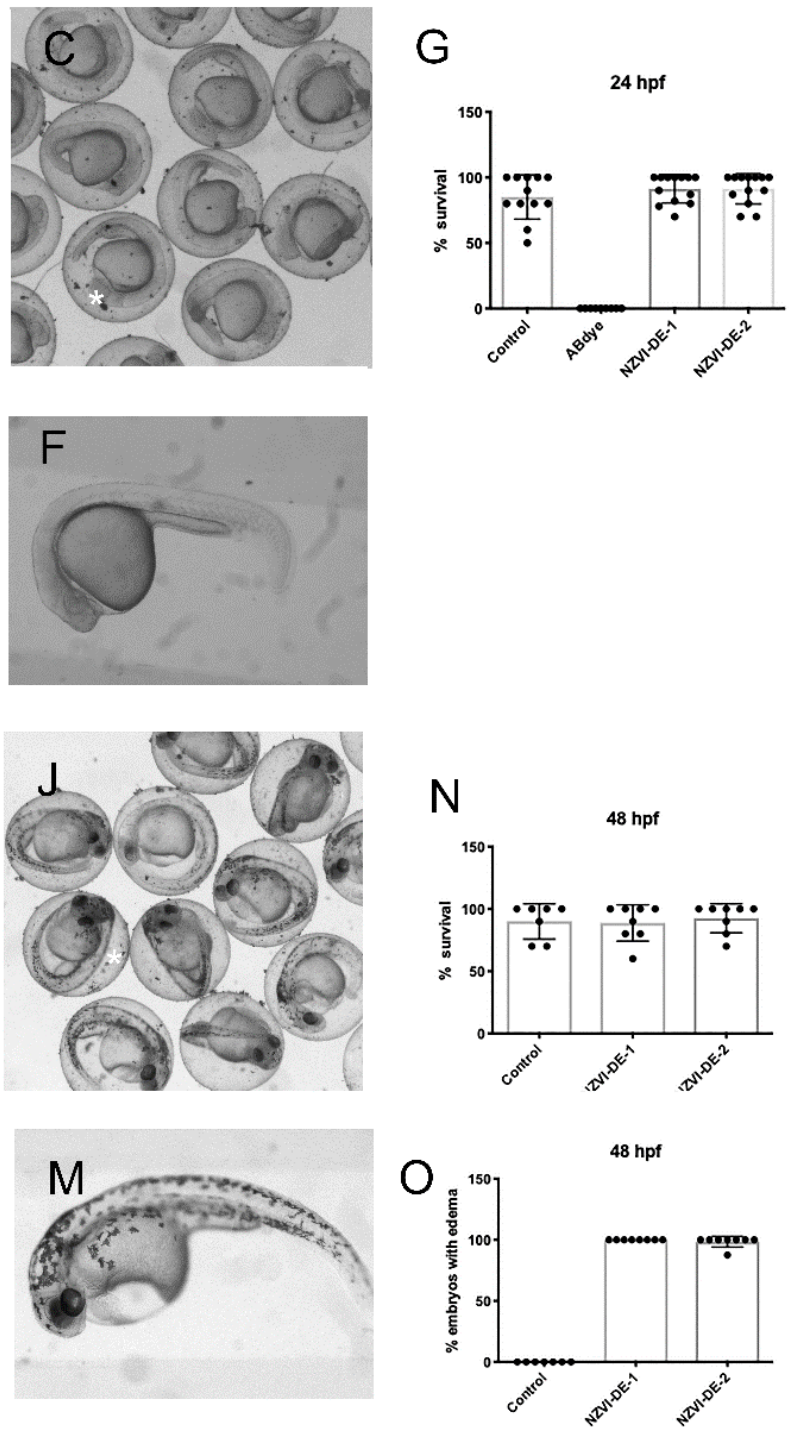

Figure 3. Zebrafish embryonic development progress in the presence of nZV-DE-1 and nZV-DE2. (A). Control embryos at $24 \mathrm{hpf}$. (B,C). Embryos at $24 \mathrm{hpf}$ proceed with development when exposed to contaminated water is treated with nZV-DE. Agglomeration of nanoparticles can be observed in the chorion (asterisk in (B,C)). (D-F). A slight delay in development is observed in nZV-DE-1 (E) and nZV-DE-2 (F) embryos compared to the control (D). (G,N) Viability is fully restored in nZV-DE treated water exposure compared to AB dye exposure. (H) Control embryos at 48 hpf. (I,J) Embryos developed until $48 \mathrm{hpf}$ as the control embryos; nevertheless, the embryos treated with nZV-DE (L,M) present cardiac edema $(\mathbf{O})$, smaller eyes curved body plan, less pigmentation, and are smaller compared to the control (K).

Nevertheless, the improvement of embryonic viability was highly significant compared to the embryos treated only with the AB dye (Figure 4). In order to determine the exact moment when the $\mathrm{AB}$ had an effect, dye cultures of $4 \mathrm{~h}$ were carried out. Here, we could observe that after $4 \mathrm{~h}$ of treatment, all embryos treated with AB dye were already dead; meanwhile, control embryos and those treated with nZV1-DE-1 and nZV1-DE-2 developed normally (Figure 4). Additionally, the embryos treated with AB dye were colored as was the chorion (Figure 4D,H), while nZV1-DE-1 and nZV1-DE-2 treated embryos followed normal development without coloration (Figure 4). Our results suggest that the treatment of nZV1-DE-1 or nZV1-DE-2 is sufficient to avoid the lethality observed in embryos exposed to $\mathrm{AB}$ dye, given that development generally proceeds at the first hours of treatment. Nevertheless, further stages of development, such as 48 and $72 \mathrm{hpf}$, were 
affected as a result of the nanoparticles present in the samples. Potential applications of nZVI-DE could mitigate the effects observed in the embryos after $24 \mathrm{~h}$ via filters where the treated water is in contact with the organism for a short period.

\section{Control}
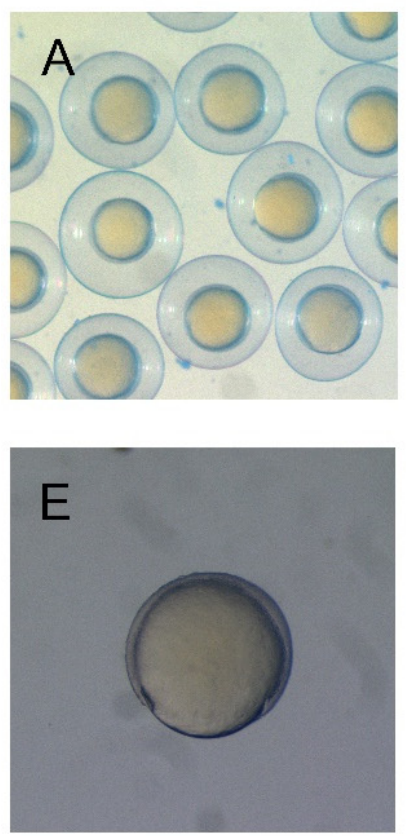

nZV-DE-1
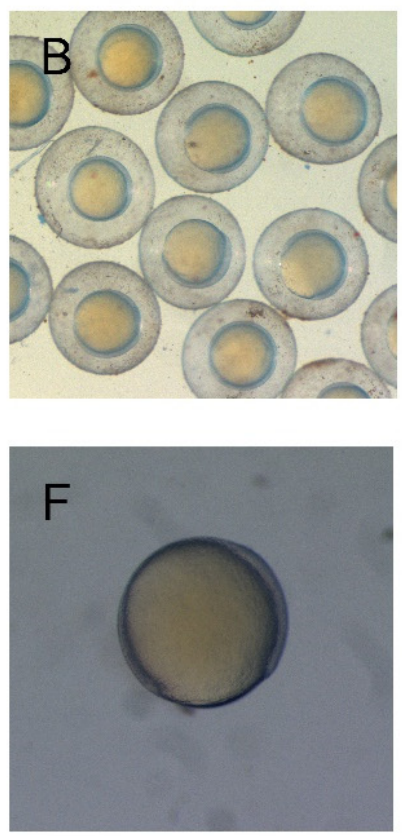

nZV-DE-2
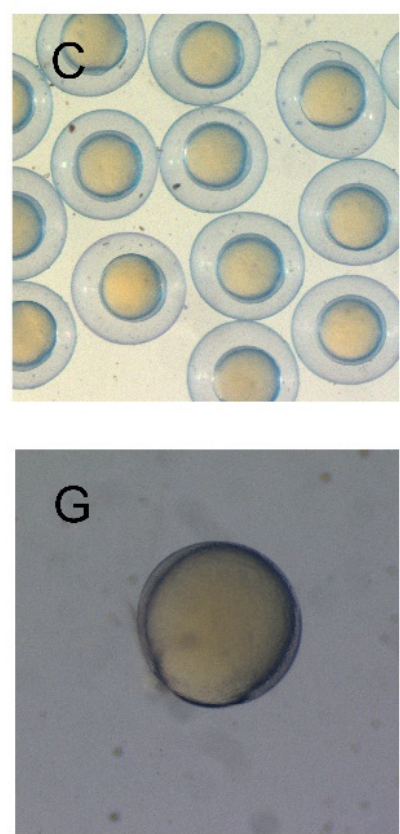

AB dye
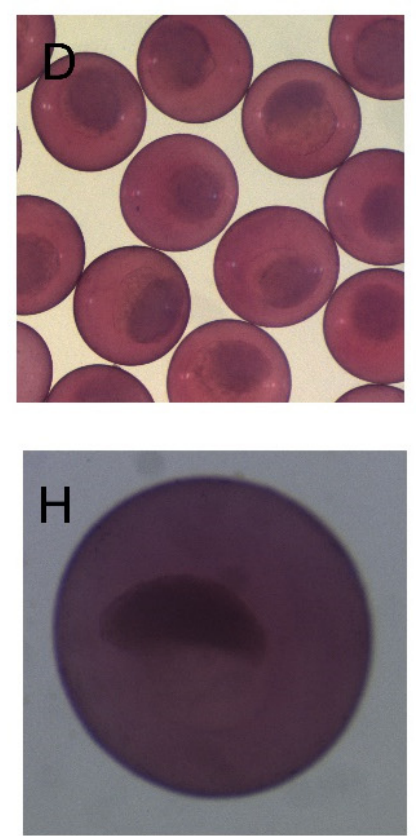

Figure 4. Early zebrafish development is restored after nZV-DE treatment. (A). Control embryos after $4 \mathrm{~h}$ of treatment. (B) Embryos treated with nZV-DE-1 develop normally. (C). Embryos treated with nZV-DE-2 develop as the control embryos. (D) Embryos treated with $\mathrm{AB}$ dye died after $4 \mathrm{~h}$ of treatment. (E-H) Higher magnifications show that embryos treated with nZV-DE (F,G) develop as the control embryos (E); meanwhile, embryos treated with AB dye absorb the dye and do not develop further and die.

\section{Discussion}

There is an increasing interest in using nanoparticles to remove different kinds of pollutants and implementing this technology as a standard filter material; however, the possible risk to aquatic life or food chains is not sufficiently clear. The design of new materials to filters needs to be accompanied with toxicological assessments.

The nZV-DE has good performance because the material was highly efficient, removing the $\mathrm{AB}$ dying in a short time. Typically, biological treatments take at least 30 days to reach removals of around $60 \%$. Furthermore, this material is superior to conventional DE filtration in addition to the removal efficiency; the treated water also does not have an acid $\mathrm{pH}$. However, the toxicological results showed all embryos exposed to the new material for more than $48 \mathrm{hpf}$ had cardiac edema, smaller eyes, and curved and smaller bodies with less pigmentation. One possible solution to implement nZV-DE material to filters is combine the treatment with a second filter that retain the nanoparticles debris. Although this material is very promising, more research is needed to deeply elucidate the toxicological effects, emulating different kinds of contacts, because if this treated water is to be released into the river, the aquatic life, such as fish, will be exposed to this water for a short period of time.

\section{Conclusions}

The nZVI-DE-1 and nZVI-DE-2 successfully removed more than $90 \%$ of one of the most widely used pollutants, acid blue, in a short time. The toxicology test of the treated water showed that wild-type zebrafish (Danio rerio) embryos developed entirely normally during the first $24 \mathrm{~h}$. However, after $48 \mathrm{~h}$, all of the embryos had cardiac edema, smaller 
eyes, and smaller bodies with less pigmentation than the control sample. Consequently, we suggest that nanoparticles technologies use supported materials and that the nanoparticle technology used to remove pollutants has limited contact with streams to avoid adverse effects on aquatic life.

Author Contributions: Conceptualization, L.B.-D.; methodology, L.B.-D., D.S., E.F.-R., H.M.P.-V., and O.S.-F.; software, L.B.-D., E.F.-R., E.J.-C. and D.S.; validation, E.F.-R. and D.S.; formal analysis, E.J.-C., D.S. and E.F.-R.; resources, H.M.P.-V. and O.S.-F.; data curation, L.B.-D.; writing-original draft preparation, L.B.-D.; writing-review and editing, L.B.-D., D.S., E.F.-R., H.M.P.-V. and O.S.-F.; supervision, L.B.-D. All authors have read and agreed to the published version of the manuscript.

Funding: This research received no external funding.

Institutional Review Board Statement: The study was conducted in compliance with local animal welfare regulations and approved by Institute's Ethical Committee (Instituto de Biotecnología, UNAM) protocol 412-30 September 2021.

Informed Consent Statement: Not applicable.

Acknowledgments: The authors thank ZEOLITECH for donating diatomaceous earth, Daniel Bahena Uribe, and Jorge Roque De La Puente of LANE, CINVESTAV, for their excellent technical help and advice on the characterization of nanoparticles, and Erick Justo Cabrera for their support in the nanoparticles synthesis. LB-D and DS thank the CICA program and Instituto de Biotecnologia UNAM for their support. In addition, LB-D thanks the Consejo Nacional de Ciencia y Tecnología (CONACYT) and their program CATEDRAS for supporting Project 285.

Conflicts of Interest: The authors declare no conflict of interest.

\section{References}

1. Ihsanullah, I.; Jamal, A.; Ilyas, M.; Zubair, M.; Khan, G.; Atieh, M.A. Bioremediation of dyes: Current status and prospects. J. Water Process Eng. 2020, 38, 101680. [CrossRef]

2. Jung, K.Y.; Lee, K.-L.; Im, T.H.; Lee, I.J.; Kim, S.; Han, K.-Y.; Ahn, J.M. Evaluation of water quality for the Nakdong River watershed using multivariate analysis. Environ. Technol. Innov. 2016, 5, 67-82. [CrossRef]

3. Bide, M. Environmentally responsible dye application. In Environmental Aspects of Textile Dyeing; Woodhead Publishing: Cambridge, UK, 2007; pp. 74-92. [CrossRef]

4. Callieri, C. Picophytoplankton in Freshwater Ecosystems: The Importance of Small-Sized Phototrophs. Freshw. Rev. 2014, 1, 1-28. [CrossRef]

5. Vikrant, K.; Giri, B.S.; Raza, N.; Roy, K.; Kim, K.H.; Rai, B.N.; Singh, R.S. Recent advancements in bioremediation of dye: Current status and challenges. Bioresour. Technol. 2018, 253, 355-367. [CrossRef] [PubMed]

6. Ammar, S.; Abdelhedi, R.; Flox, C.; Arias, C.; Brillas, E. Electrochemical degradation of the dye indigo carmine at boron-doped diamond anode for wastewaters remediation. Environ. Chem. Lett. 2006, 4, 229-233. [CrossRef]

7. Khelifi, E.; Gannoun, H.; Touhami, Y.; Bouallagui, H.; Hamdi, M. Aerobic decolourization of the indigo dye-containing textile wastewater using continuous combined bioreactors. J. Hazard. Mater. 2008, 152, 683-689. [CrossRef]

8. Pacheco-Álvarez, M.O.A.; Picos, A.; Pérez-Segura, T.; Peralta-Hernández, J.M. Proposal for highly efficient electrochemical discoloration and degradation of azo dyes with parallel arrangement electrodes. J. Electroanal. Chem. 2019, 838, $195-203$. [CrossRef]

9. Saleh, S.M. ZnO nanospheres based simple hydrothermal route for photocatalytic degradation of azo dye. Spectrochim. Acta Part A Mol. Biomol. Spectrosc. 2019, 211, 141-147. [CrossRef]

10. Wang, F.; Huang, J.; Xu, J. Continuous-flow synthesis of azo dyes in a microreactor system. Chem. Eng. Process.-Process Intensif. 2018, 127, 43-49. [CrossRef]

11. Ziarani, G.M.; Moradi, R.; Lashgari, N.; Kruger, H.G. Azo Dyes, Metal-Free Synthetic Organic Dyes; Elsevier: Amsterdam, The Netherlands, 2018; ISBN 9780128156476.

12. Răducan, A.; Puiu, M.; Oancea, P.; Colbea, C.; Velea, A.; Dinu, B.; Mihăilescu, A.M.; Galaon, T. Fast decolourization of Indigo Carmine and Crystal Violet in aqueous environments through micellar catalysis. Sep. Purif. Technol. 2019, 210, 698-709. [CrossRef]

13. Fan, J.; Guo, Y.; Wang, J.; Fan, M. Rapid decolorization of azo dye methyl orange in aqueous solution by nanoscale zerovalent iron particles. J. Hazard. Mater. 2009, 166, 904-910. [CrossRef] [PubMed]

14. Sharma, H.; Shirkot, P. Bioremediation of azo dyes using biogenic iron nanoparticles. J. Microbiol. Exp. 2019, 7, 12-15. [CrossRef]

15. Quinn, J.; Geiger, C.; Clausen, C.; Brooks, K.; Coon, C.; O’Hara, S.; Krug, T.; Major, D.; Yoon, W.S.; Gavaskar, A.; et al. Field demonstration of DNAPL dehalogenation using emulsified zero-valent iron. Environ. Sci. Technol. 2005, 39, 1309-1318. [CrossRef]

16. Xiao, C.; Li, H.; Zhao, Y.; Zhang, X.; Wang, X. Green synthesis of iron nanoparticle by tea extract (polyphenols) and its selective removal of cationic dyes. J. Environ. Manag. 2020, 275, 111262. [CrossRef] [PubMed] 
17. Zhang, M.; Bacik, D.B.; Roberts, C.B.; Zhao, D. Catalytic hydrodechlorination of trichloroethylene in water with supported CMC-stabilized palladium nanoparticles. Water Res. 2013, 47, 3706-3715. [CrossRef] [PubMed]

18. Raychoudhury, T.; Naja, G.; Ghoshal, S.; Ortiz De La Plata, G.B.; Alfano, O.M.; Cassano, A.E.; Cook, S.M.; USEPA; Jia, H.; Wang, C.; et al. Preparation and characterization of zero valent Iron nanoparticles. Last Verif. 2012, 137, 53-59. Available online: http / / www.epa.gov/rpdweb00/docs/cleanup/nanotechnology/chapter-2-zero-valent.pdf (accessed on 7 October 2019).

19. Krysanov, E.Y.; Pavlov, D.S.; Demidova, T.B.; Dgebuadze, Y.Y. Effect of Nanoparticles on Aquatic Organisms. Biol. Bull. Russ. Acad. Sci. 2010, 37, 406-412. [CrossRef]

20. Wang, P.; Ma, Q.; Hu, D.; Wang, L. Removal of Reactive Blue 21 onto magnetic chitosan microparticles functionalized with polyamidoamine dendrimers. React. Funct. Polym. 2015, 91-92, 43-50. [CrossRef]

21. Liu, J.; Jiang, J.; Meng, Y.; Aihemaiti, A.; Xu, Y.; Xiang, H.; Gao, Y.; Chen, X. Preparation, environmental application and prospect of biochar-supported metal nanoparticles: A review. J. Hazard. Mater. 2020, 388, 122026. [CrossRef] [PubMed]

22. AbuKhadra, M.R.; Eid, M.H.; Allam, A.A.; Ajarem, J.S.; Almalki, A.M.; Salama, Y. Evaluation of different forms of Egyptian diatomite for the removal of ammonium ions from Lake Qarun: A realistic study to avoid eutrophication. Environ. Pollut. 2020, 266, 115277. [CrossRef]

23. ElSayed, E.E. Natural diatomite as an effective adsorbent for heavy metals in water and wastewater treatment (a batch study). Water Sci. 2018, 32, 32-43. [CrossRef]

24. Erdem, E.; Çölgeçen, G.; Donat, R. The removal of textile dyes by diatomite earth. J. Colloid Interface Sci. 2005, 282, 314-319. [CrossRef]

25. Huang, X.; Wang, A.; Luo, J.; Gao, Y.; Guan, L.; Zhang, P.; Liu, F.; Mu, W.; Li, B. Lambda-cyhalothrin-loaded nanocapsules pose an unacceptable acute toxicological risk to zebrafish (Danio rerio) at the adult and larval stages but present an acceptable risk to embryos. J. Hazard. Mater. 2022, 422, 126853. [CrossRef] [PubMed]

26. Chaves, R.S.; Guerreiro, C.S.; Cardoso, V.V.; Benoliel, M.J.; Santos, M.M. Toxicological assessment of seven unregulated drinking water Disinfection By-products (DBPs) using the zebrafish embryo bioassay. Sci. Total Environ. 2020, 742, 140522. [CrossRef] [PubMed]

27. Xu, K.; Ai, W.; Wang, Q.; Tian, L.; Liu, D.; Zhuang, Z.; Wang, J. Toxicological effects of nanoplastics and phenanthrene to zebrafish (Danio rerio). Gondwana Res. 2021, 52. [CrossRef]

28. Ali, S.; van Mil, H.G.J.; Richardson, M.K. Large-Scale assessment of the zebrafish embryo as a possible predictive model in toxicity testing. PLoS ONE 2011, 6, 0021076. [CrossRef] [PubMed]

29. Fu, F.; Dionysiou, D.D.; Liu, H. The use of zero-valent iron for groundwater remediation and wastewater treatment: A review. J. Hazard. Mater. 2014, 267, 194-205. [CrossRef] [PubMed]

30. Westerfield, M. A Guide for the Laboratory Use of Zebrafish (Danio Rerio), 4th ed.; Shevchenko, V.H.A., Ed.; University of Oregon Press: Eugene, OR, USA, 2000.

31. Kimmel, C.B.; Ballard, W.W.; Kimmel, S.R.; Bonnie, U. Zfin Embyonic Developmental Stages. Dev. Dyn. 1995, 10, 253-310. [CrossRef] [PubMed]

32. Machado, G.E.; Pereyra, A.M.; Rosato, V.G.; Moreno, M.S.; Basaldella, E.I. Improving the biocidal activity of outdoor coating formulations by using zeolite-supported silver nanoparticles. Mater. Sci. Eng. C 2019, 98, 789-799. [CrossRef] [PubMed]

33. Yuan, P.; Liu, D.; Fan, M.; Yang, D.; Zhu, R.; Ge, F.; Zhu, J.X.; He, H. Removal of hexavalent chromium [Cr(VI)] from aqueous solutions by the diatomite-supported/unsupported magnetite nanoparticles. J. Hazard. Mater. 2010, 173, 614-621. [CrossRef]

34. Guatame-Garcia, A. Buxton, M. The Use of Infrared Spectroscopy to Determine the Quality of Carbonate-Rich Diatomite Ores. Minerals 2018, 8, 120. [CrossRef]

35. Al-Ghouti, M.A.; Khraisheh, M.A.M.; Allen, S.J.; Ahmad, M.N. The removal of dyes from textile wastewater: A study of the physical characteristics and adsorption mechanisms of diatomaceous earth. J. Environ. Manag. 2003, 69, 229-238. [CrossRef] [PubMed]

36. Crane, R.A.; Sapsford, D.J. Sorption and fractionation of rare earth element ions onto nanoscale zerovalent iron particles. Chem. Eng. J. 2018, 345, 126-137. [CrossRef]

37. Deng, J.; Dong, H.; Zhang, C.; Jiang, Z.; Cheng, Y.; Hou, K.; Zhang, L.; Fan, C. Nanoscale zero-valent iron/biochar composite as an activator for Fenton-like removal of sulfamethazine. Sep. Purif. Technol. 2018, 202, 130-137. [CrossRef]

38. Chen, Z.X.; Jin, X.Y.; Chen, Z.; Megharaj, M.; Naidu, R. Removal of methyl orange from aqueous solution using bentonitesupported nanoscale zero-valent iron. J. Colloid Interface Sci. 2011, 363, 601-607. [CrossRef] [PubMed]

39. Wu, G.; Cheng, Y.; Ren, Y.; Wang, Y.; Wang, Z.; Wu, H. Synthesis and characterization of $\gamma$-Fe2O3@C nanorod-carbon sphere composite and its application as microwave absorbing material. J. Alloys Compd. 2015, 652, 346-350. [CrossRef]

40. Shah, S.Z.H.; Khan, U.; Riaz, S.; Naseem, S. Effect of pH on Iron Oxide Nanoparticles; Elsevier Ltd.: Amsterdam, The Netherlands, 2015; Volume 2.

41. Basheer, A.A. New generation nano-adsorbents for the removal of emerging contaminants in water. J. Mol. Liq. 2018, 261, 583-593. [CrossRef]

42. Garg, S.; Jiang, C.; Waite, T.D. Impact of $\mathrm{pH}$ on Iron Redox Transformations in Simulated Freshwaters Containing Natural Organic Matter. Environ. Sci. Technol. 2018, 52, 13184-13194. [CrossRef]

43. Nosrati, A.; Larsson, M.; Lindén, J.B.; Zihao, Z.; Addai-Mensah, J.; Nydén, M. Polyethyleneimine functionalized mesoporous diatomite particles for selective copper recovery from aqueous media. Int. J. Miner. Process. 2017, 166, 29-36. [CrossRef] 
44. Lowe, B.M.; Skylaris, C.K.; Green, N.G. Acid-base dissociation mechanisms and energetics at the silica-water interface: An activationless process. J. Colloid Interface Sci. 2015, 451, 231-244. [CrossRef]

45. de Almeida, V.O.; Pereira, T.C.B.; de Teodoro, L.S.; Escobar, M.; Ordovás, C.J.; dos Santos, K.B.; Weiler, J.; Bogo, M.R.; Schneider, I.A.H. On the effects of iron ore tailings micro/nanoparticles in embryonic and larval zebrafish (Danio rerio). Sci. Total Environ. 2021, 759, 143456. [CrossRef] 